\title{
The Acquisition of Social Work Interviewing Skills in a Web-based and Classroom Instructional Environment: Preliminary Findings
}

\author{
Philip M. Ouellette \\ Valerie Chang
}

\begin{abstract}
Little is known regarding the learning of social work practice skills in a Web-based onlineenvironment, most especially, social work interviewing skills. This article presents a review of the research methodology used to initiate a study to explore the similarities and differences of two groups of students who were taught interviewing skills in a classroom-based teaching environment with thosetaught in a Web-based instructional environment during the same 15-week period. Students' background characteristics and their perceptions of their learning experience and skill acquisition are reported as preliminary findings.
\end{abstract}

Keywords: Telelearning, WEB-based instruction, social work interviewing, Social Work practice

T he infusion of technology into social work courses has progressed exponentially in the past few years. Some have indicated "no significant difference" between the efficacies of learning outcomes with courses taught in an online learning environment versus those taught in a face-toface classroom-based learning setting (Macy, Rooney, Hollister \& Freddolino, 2001). Little is known, however, regarding the learning of social work practice and interviewing skills in a Web-based online instructional environment.

To date, most of what has been done to teach social work practice skills with the use of technology has been conducted through the use of Web-enhanced instructional format, which combines the classroom with some Web-based instruction (Ouellette, 1999). Doubt as to whether interviewing skills can realistically be learned in an online environment still prevails in the field of social work education (Burton \& Seabury, 1999). Research specifically addressing the extent to which social work students learn actual interviewing and practice skills from an online course is needed.

This paper presents the preliminary findings of a recent study initiated to explore the similarities and differences in the acquisition of basic interviewing skills between two groups of students enrolled in an undergraduate meth-

Philip Ouellette, Ph.D. is Associate Professor and Valerie Chang is Professor at the Indiana University School of Social Work, Indianapolis, IN 46202.

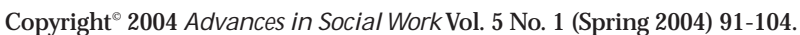
Indiana University School of Social Work. 
ods course in social work. One group was taught interviewing skills in a traditional three hours per week classroom-based teaching environment. The other group was taught interviewing skills strictly in a Web-based instructional environment with no face-to-face contact with the instructor. Instruction for both groups took place during the same 15-week period. A description of the research project and preliminary findings regarding student perceptions of their learning experience follows. In addition, examples of pedagogical strategies used in each of the instructional settings to teach basic interviewing skills will be outlined.

\section{BACKGROUND LITERATURE}

Learning social work practice skills in an online instructional environment has al ready been suggested as a possibility if one adheres to adult learning principles (Friedman, 2002) and effective active learning paradigms which are conducive to a technology-supported instructional environment (environment (Brooks, 1997; Ewell \& Jones, 1996; Ouellette \& Sells, 2003). Attempts have been made to teach an advanced practice course by combining the use of several technological mediums, such as teleconferencing and Web-instruction (Ouellette $\&$ Sells, 2001), the results of which have shown much promise. In addition, some have suggested that the task of teaching and learning social work practice in an online environment can greatly be facilitated if careful attention is paid to proper preparation and by following a step-by-step approach to course design of a technology-supported learning environment (Ouellette \& Sells, 2003; Brooks, 1997).

One criticism often heard from social work educators with respect to the use of technology as an instructional medium is that this environment is not particularly conducive to the training of social work practitioners (Kreuger, 1997). As a result, many have been reluctant to offer their programs in a distance education format and have been suspicious of the use of technology in education and practice (Burton \& Seabury, 1999; Butterfield, 1998; Marson, 1997). This argument is largely articulated based on the unsubstantiated notion that only a face-to-face, classroom-based social environment provides meaningful interaction between students and instructor. From this perspective, the teacher becomes the major communicator of new information and influence for the students.

On the other hand, a technology-based learning environment shifts a considerable amount of power, authority, and control from the instructor to the students (Jaffee, 1998). It is morecompatible with progressive educational approaches that are characterized by a climate of mutual collaboration between student and teacher in developing learning activities and goals (Trigg \& Cordova, 1987).

\section{The Birth of Telelearning}

Since the early 1990s educational experts coming from disciplines other than social work have been examining the impact of teaching and learning in WEBbased instructional environments (Harasim, 1999). As a result of the pioneering work of many technology-sensitive educators, a new concept has emerged, that of telelearning. Telelearning is understood to mean the use, at school or at home, of multimedia computers networked to other computers for learning purposes (TL*NCE, 1995). This means that learners, using computers networked together, 
communicate from one site to the other using a variety of information sources. Networked computers permit students to expand their acquisition of new information beyond a single instructor.

Another term that describes the use of computer networks for teaching and learning is "Network Learning" (Kearsley, 1993). It has been suggested that learning networks, based on asynchronous communication using computer technology, offer additional opportunities for active participation between learners (Harasim, Hiltz, Teles \& Turoff, 1995). The difference between traditional forms of asynchronous communication used in the conventional classroom, such as an integrative paper, a quiz, or exam, and asynchronous communication in an electronic medium, such as the use of e-mail and a discussion board, lies mainly in the following. The speed with which feedback can be provided is accelerated, the nature of the setting used to communicate ideas can be in one's home or work setting, and the ability to easily and quickly disseminate ideas to peers or a large number of people is greatly enhanced by the electronic medium. It is for this reason that asynchronicity in an electronic medium has been suggested as having the potential to elevate the quality of student interaction and participation (Doherty, 1998).

\section{RESEARCH DESCRIPTION}

Irrespective of the training context or instructional medium being used, the transfer of learned skills from the training setting to actual practice continues to be a challenge for social work educators. With respect to learning interviewing skills, there are many factors that contribute to a student's skill acquisition. For example, these may include the quality of the instruction, teaching methods that are utilized, opportunities for skills practice, opportunities to practice observation skills, and opportunities to self-evaluate performance and provide constructive feedback to others.

To further enhance our understanding of how interviewing skills are acquired, irrespective of the teaching medium, a study was initiated with two groups of undergraduate students enrolled in two different sections of a social work practice course in generalist social work. Both instructors adhered to similar teaching and learning principles. One section of the course was taught in a classroombased instructional environment, while the other was taught in a Web-based instructional environment. This study explored the similarities and differences between two groups of students who were taught interviewing skills in different instructional contexts.

Design: The study employed a quasi-experimental design (Cook \& Campbell, 1979). Students registered in the BSW program were provided with the opportunity to enroll for a required core practice course in one of two sections having the same number of students. The primary instructional method for one section was the use of a classroom-based instructional format. The group met once each week for a three-hour class session during the 15-week semester. The other section followed a Web-based instructional format with no face-to-face meetings between the instructor and the students. The online students received a different unit of study each week, with learning objectives and learning activities to be 
completed on a weekly basis. Both courses followed the same semester and were implemented during the same timeframe.

Once the semester was completed, all students who participated in the study were asked to attend a face-to-face session at the university to conduct a 10minute interview segment with a simulated client who was coached and trained by the two investigators. The interview was videotaped for further analysis by independent evaluators.

Selection Process: Once the course was initiated, students from each class were invited to voluntarily participate in a study to examine the acquisition of practice skills. A total of 60 students were invited to participate in the study. A consent form outlining the purpose of the study, what was to be expected, and what steps were taken to ensure confidentiality, was provided. A demographic survey questionnaire was provided, which was completed by those students who chose to participate. In response to our invitation, a total of 30 students agreed to voluntarily participate in the study. Table 1 outlines the number of students from each class section who participated in the study.

\begin{tabular}{|l|c|c|}
\hline \multicolumn{3}{|l|}{ Table 1: Study Participants by Section } \\
\hline Section & Total Number & Percentage \\
\hline Classroom setting & 14 & $46.6 \%$ \\
\hline Online setting & 16 & $53.3 \%$ \\
\hline Totals & 30 & \\
\hline
\end{tabular}

Demographic Characteristics: Table 2 presents the gender, age, and ethnic characteristics of the 30 student beneficiaries. As can be seen, the majority of students (93.3\%) were female. More than half (53.3\%) were between the ages of 20 and 29 , with $30 \%$ being between the ages of 30 and 39 . Only $16.6 \%$ were older than 40, with $60 \%$ being Caucasian and 33.3\% African American. In addition, 3.3\% were Hispanic and 3.3\% were from other cultural backgrounds. It is interesting to note that both groups had similar characteristics.

Table 3 presents the number of students with no online course experience and those with prior experience in taking online courses. Of the students in the study, $66.6 \%$ had never taken an online course, $10 \%$ indicated they had one previous online training experience, and only $24 \%$ reported having had two or more online course experiences, all of which were part of the online group.

Table 4 presents the number of students who indicated they had previous experience with using interviewing skills either through their existing employment situation or volunteer work. Of the students involved in the study, 83.3\% reported having had no prior experience with the use of interviewing skills.

Using a t-test and Chi-Square measure, Table 5 compares the statistical differences between the background characteristics of students in both groups. It is interesting to note that except for the online group's age and their prior experience with online courses, both groups are very similar. 


\begin{tabular}{|c|c|c|c|c|}
\hline Gender & Total & $\begin{array}{l}\text { Percentage } \\
\text { Number }\end{array}$ & Online & Classroom \\
\hline Male & 2 & $6.67 \%$ & 2 (12.5\%) & None \\
\hline Female & 28 & $93.3 \%$ & 14(87.5\%) & 14 (100\%) \\
\hline Totals & 30 & & 16 & 14 \\
\hline Age Range & Number & Percentage & Online & Classroom \\
\hline $20-29$ & 16 & $53.3 \%$ & 7 (43.75\%) & 9 (64.29\%) \\
\hline 30-39 & 9 & $30 \%$ & 5 (31.25\%) & 4 (28.57\%) \\
\hline $40+$ & 5 & $16.67 \%$ & $4(25 \%)$ & 1 (7.14\%) \\
\hline Totals & 30 & & 16 & 14 \\
\hline Ethnicity & Number & Percentage & Online & Classroom \\
\hline $\begin{array}{l}\text { African } \\
\text { American }\end{array}$ & 10 & $33.33 \%$ & $6(37.5 \%)$ & $4(28.5 \%)$ \\
\hline Hispanic & 1 & $3.33 \%$ & 1 (6.25\%) & 0 \\
\hline Caucasian & 18 & $60 \%$ & $9(56.25 \%)$ & $9(64.2 \%)$ \\
\hline Other & 1 & $3.33 \%$ & 0 & 1 (7.1\%) \\
\hline Totals & 30 & & 16 & 14 \\
\hline
\end{tabular}

\begin{tabular}{|l|l|l|l|l|}
\hline \multicolumn{6}{|c|}{ Table 3: } & Number of Online Courses Taken & Classroom \\
\hline Number & Percentage & Online & $11(78.5 \%)$ \\
\hline None & 20 & $66.67 \%$ & $9(56.25 \%)$ & $3(21.4 \%)$ \\
\hline 1 & 3 & $10 \%$ & 0 & 0 \\
\hline 2 & 4 & $13.3 \%$ & $4(25 \%)$ & 0 \\
\hline 3 & 1 & $3.33 \%$ & $1(6.25 \%)$ & 0 \\
\hline 4 & 2 & $6.67 \%$ & $2(12.5 \%)$ & 14 \\
\hline Totals & 30 & & 16 & \\
\hline
\end{tabular}




\begin{tabular}{|c|c|c|l|l|}
\hline \multicolumn{2}{|c|}{ Table 4: Prior Experience with Interviewing Skills } \\
$\begin{array}{c}\text { Prior } \\
\text { Experience }\end{array}$ & $\begin{array}{c}\text { Total } \\
\text { Number }\end{array}$ & Percentage & Online & Classroom \\
\hline Yes & 5 & $16.67 \%$ & $2(12.5 \%)$ & $3(21.4 \%)$ \\
\hline No & 25 & $83.3 \%$ & $14(87.5 \%)$ & $11(78.5 \%)$ \\
\hline & 30 & & 16 & 14 \\
\hline
\end{tabular}

\begin{tabular}{|l|c|c|c|c|}
\hline Table 5: Comparison of Background Characteristics & \\
\hline Background Characteristics & $\begin{array}{c}\text { Online } \\
\text { Group } \\
\mathbf{( N = 1 6 )}\end{array}$ & $\begin{array}{c}\text { Classroom } \\
\text { Group } \\
\mathbf{( N = 1 3 )}\end{array}$ & $\mathbf{t}$ & $\mathbf{P}$ \\
\hline Age & 32.69 & 25.46 & 2.037 & .052 \\
\hline Credit hours & 12.69 & 13.85 & -1.3382 & .192 \\
\hline Paid work hours per week & 21.81 & 21.85 & -.005 & .996 \\
\hline S231 importance & 8.38 & 8.85 & -1.416 & .168 \\
\hline Grade expected & 7.25 & 7.38 & -.227 & .822 \\
\hline Overall GPA & 3.15 & 3.11 & .303 & .764 \\
\hline Last semester GPA & 3.37 & 3.41 & -.276 & .785 \\
\hline & & & Chi & p \\
\hline Percent of Ethnicity & $43.8 \%$ & $38.5 \%$ & .083 & .774 \\
\hline $\begin{array}{l}\text { Percent of prior experience } \\
\text { with online courses }\end{array}$ & $43.8 \%$ & $0 \%$ & 7.49 & .006 \\
\hline
\end{tabular}

\section{Instructional Methods}

Classroom Setting: For the classroom-based instructional setting, the following methods were used to learn and practice basic interviewing skills. The classroom course used a competency-based model, with skills defined and operationalized using clear, behavioral, observable, specific terms and an evaluation system for assessing levels of competency (Clark \& Horejsi, 1979). The students learned basic interviewing skills by focusing on one skill group at a time, adding new skills in each class (Chang \& Scott, 1999). In this class, students learned basic interpersonal skills; communicating involvement; observing, active listening, and exploring skills; reflecting, questioning; and seeking clarification. The learning sequence involved reading, writing, discussing, practicing, and evaluating. After reading about the appropriate use of a group of skills, the students had opportunities to use the skills by writing responses to client statements. Discussion of skill usage was promoted by showing videotaped examples of student interviews. Using transcripts of the interview, students discussed individual transactions, use of specific skills, 
and the overall process of the interview. Students then practiced simulated interviews with other students in the role of client.

Receiving immediate evaluation was an important part of the learning process. Each interview was followed by an evaluation. The person in the role of client gave feedback to the person in the role of social worker. The person in the role of social worker identified his/her strengths and weaknesses. A third person in the role of peer supervisor completed a detailed evaluation form. Likert-type scales measure overall skill categories and dichotomous categories assess specific behaviors. As each group of new skills was learned, the students also learned how to evaluate the appropriate use of these skills. This immediate feedback provided students a chance to identify strengths and begin working to correct problem areas. Safety was created, because all students were facing similar learning challenges, feedback was constructive, and encouragement was freely given. At the end of the semester, each student completed a final 10-minute videotaped interview with another student from the class as the client. The student wrote a transcript of the interview and evaluated it. The instructor met with each student to review both his/her videotape and evaluation of the videotape.

Web-based Setting: In the Web-based instructional environment, several pedagogical strategies were used to learn and practice interviewing skills. These were: (i) interactive notes, (ii) self-test, (iii) collaborative-learning activities, (iv) video demonstrations, (v) skills practice exercises, (vi) selfassessment reports, (vii) peer reviews, and (viii) instructor feedback. The first was the use of a series of "interactive notes," where students were to develop conceptual skills about the interviewing process. These notes complimented traditional reading materials. Interviewing skills were divided into five different stages of the interview process. For the purpose of this study, examination of skill development focused primarily on specific interviewing skills associated with the beginning stages of the interview, that is, the Social or Engagement and the Problem Identification Stage. Embedded learning activities made the notes interactive. As a student explored the interactive notes on different micro-skills of a particular stage of the interview, learning assignments were integrated to permit the student to reflect on the content. These assignments required the student to stop his/her exploration of the notes, complete a brief learning task that required some critical thought, and upload the assignment to a specific electronic drop box. A series of learning tasks of this kind were embedded throughout the interactive notes. This strategy provided the instructor with some initial feed back regarding how the student was progressing in the development of basic conceptual skills about a particular interviewing strategy.

The second pedagogical strategy was the extensive use of "self-tests." A selftest is a short multiple choice or short answer online quiz that reviews the content of the required readings and interactive notes. Self-tests provide opportunities for immediate feedback regarding the student's level of understanding or the meaning of specific interviewing strategies. To enhance the development of conceptual skills, students were then required to engage in a 
collaborative learning exercise. This was facilitated by the use of an electronic bulletin board of a small group discussion forum using asynchronous communication. This provided an opportunity for the students to articulate the meaning of certain interviewing strategies to one another and acquire additional input from peers and the instructor on how certain strategies can be implemented in an interview.

The next step in the learning process involved the development of actual executive skills through practice. To set the stage for practice, a series of small streaming video interview segments were provided online that were easily downloadable through regular connection lines. A discovery learning strategy was used to guide students towards implementing a particular interviewing skill. The initial video segment illustrated the beginning moments of the interview between a social worker and a fictitious client. Only the sound track of the fictitious client was heard, but the social worker in the interview could be seen. After a particular segment was completed, the students were to provide examples of the kinds of questions and/ or statements that could be used to solicit the client responses they were hearing. These suggestions were provided in an observation form and forwarded to the instructor. This technique provided students with an opportunity to examine the multiple ways a message can be articulated while acquiring similar responses from clients. In the second part of the exercise, the student reviewed the same interview segment, but this time with what was actually said by the interviewer. Questions and answers were compared, with the surprising results that student questions and guesses were at times far superior to what was actually said in the training video. After reviewing several segments of the video using this process, the students were then asked to practice the skills associated with a particular stage of the interview. To do this, each student selected a friend, classmate, or relative at home to role-play and practice a particular skill during the initial stages of the interview. These practice sessions were videotaped either at home or by accessing videotaping facilities at the university. The students were to practice and videotape each interview segment several times before advancing to the next step. The final step involved using a self-assessment strategy and peer reviews. By using an observation tool provided online, each student selected his/her last practice segment and self-evaluated the performance. A peer was asked to assist by reviewing the same segment and providing his/her own comments and reflections. These practice tapes, along with self-evaluation reports and peer reviews, were submitted to the instructor for additional feedback. This process was repeated for each stage of the interview process.

Once the video-tape practice sessions were completed, each student was then required to conduct an entire 30-to-45 minute interview which demonstrated their skill acquisition at each stage of the interview process. This tape was submitted to a peer for a peer review, which was completed using a behavioral checklist and observation sheet designed for this purpose. The results of the peer review were submitted to the instructor. 


\section{DATACOLLECTION PROCEDURES}

Three sets of data were collected for this study. The first set of data was based on information regarding the demographic nature of the study participants. A second set was collected to gather information on student perspectives of their learning experience and determine the degree to which they perceived their level of skill acquisition. A third set of data were collected to acquire information on the acquisition of actual interviewing skills.

Instruments: Two instructors, respectively, administered all evaluative instruments used for this study. Specifically, three instruments were used to collect information from student beneficiaries.

(1) Demographic Survey: At the time of student recruitment, a pre-interview demographic survey questionnaire was used to gather the demographic characteristics of students who chose to voluntarily participate in the study. This questionnaire provided information on age, ethnicity, gender, prior experience using interviewing skills, and prior experience with taking online courses.

(2) End-of-semester survey questionnaire: Once the course was completed, students in the study were requested to complete an end-of-semester questionnaire to gather subjective information on the students' perception of the clarity and effectiveness of the learning exercises used to teach interviewing skills, irrespective of the instructional medium used. Likert-type scales measures were used to acquire data on the following characteristics: (i) organization of learning exercises, (ii) the extent to which interest levels were sparked by the learning exercises, (iii) clarity of instructions, (iv) student perception regarding implementing interviewing skills, (v) student perception of their learning experience, and (vi) student's level of confidence with the use of interviewing skills. In addition, the students were provided an opportunity to add subjective data for each of the characteristics.

(3) Videotaped Interviews: After the course was completed and grades were turned in, the students were invited to conduct a 10-minute interview with a simulated client. This interview was conducted and videotaped at the university. The simulated client was trained and role-played by graduate-level students and one undergraduate senior-level social work student. All three students used for the client simulation were coached and trained to role-play the same simulated client role-play scenario. The students used for the simulated client were neither part of either the classroom or online group being studied, nor were they known to the study participants.

\section{ANALYSIS}

For the purpose of the article, qualitative and quantitative data analysis was conducted on information collected from the demographic survey and the end-ofsemester survey questionnaire. A t-test and Chi-Square was used to determine the extent that the two groups were similar or different with respect their background characteristics. A t-test was used to determine if there was a significant difference between student responses regarding their perceptions of the clarity and effectiveness of the learning exercises used and their perception of their level of skill acquisition. Qualitative data collected from the two survey questionnaires 
were coded and examined using NIVO software to assess student attributes and emerging themes from their comments. The qual itative data were reviewed independently by the two co-investigators.

Data from the videotaped interviews are currently being evaluated by independent evaluators, the results of which will be reported at a later date.

\section{Preliminary Findings}

The following tables summarize findings from data collected from the two survey questionnaires. Tables 6 and 7 present information on how students in

\begin{tabular}{|l|c|c|c|c|c|}
\hline \multicolumn{7}{|l|}{ Table 6: Clarity and Effectiveness of Learning Exercises } \\
\hline $\begin{array}{l}\text { Online Respondents } \\
\text { Reporting N=16 }\end{array}$ & $\begin{array}{c}\text { Strongly } \\
\text { Disagre } \\
(\mathbf{1})\end{array}$ & $\begin{array}{c}\text { Disagree } \\
\mathbf{( 2 )}\end{array}$ & $\begin{array}{c}\text { Undecided } \\
\mathbf{( 3 )}\end{array}$ & $\begin{array}{c}\text { Agree } \\
\mathbf{( 4 )}\end{array}$ & $\begin{array}{c}\text { Strongly } \\
\text { Agree } \\
\mathbf{( 5 )}\end{array}$ \\
\hline Exercises well-organized & 0 & 0 & $2(12.5 \%)$ & $5(31.25 \%)$ & $(56.25 \%)$ \\
\hline $\begin{array}{l}\text { Exercises sparked my } \\
\text { interest }\end{array}$ & 0 & $3(18.75 \%)$ & 0 & $5(31.25 \%)$ & $8(50 \%)$ \\
\hline Enjoyed participating & 0 & $1(6.25 \%)$ & $1(6.25 \%)$ & $7(43.75 \%)$ & $7(43.75 \%)$ \\
\hline Instructions were clear & 0 & 0 & $1(6.25 \%)$ & $7(43.75 \%)$ & $8(50 \%)$ \\
\hline $\begin{array}{l}\text { Can implement } \\
\text { interviewing skills }\end{array}$ & $1(6.25 \%)$ & $1(6.25 \%)$ & $2(12.5 \%)$ & $7(43.75 \%)$ & $5(31.25 \%)$ \\
\hline $\begin{array}{l}\text { Learned a lot from } \\
\text { activities }\end{array}$ & 0 & $2(12.5 \%)$ & 0 & $10(62.5 \%)$ & $4(25 \%)$ \\
\hline $\begin{array}{l}\text { Achieved a high level } \\
\text { of confidence with } \\
\text { interviewing skills }\end{array}$ & $2(12.5 \%)$ & $1(6.25 \%)$ & $2(12.5 \%)$ & $8(50 \%)$ & $3(18.75 \%)$ \\
\hline
\end{tabular}

\begin{tabular}{|c|c|c|c|c|c|}
\hline $\begin{array}{l}\text { Online Respondents } \\
\text { Reporting } \mathrm{N}=13\end{array}$ & $\begin{array}{l}\text { Strongly } \\
\text { Disagree } \\
\text { (1) }\end{array}$ & $\begin{array}{c}\text { Disagree } \\
\text { (2) }\end{array}$ & $\begin{array}{c}\text { Undecided } \\
\text { (3) }\end{array}$ & $\begin{array}{l}\text { Agree } \\
\text { (4) }\end{array}$ & $\begin{array}{l}\text { Strongly } \\
\text { Agree } \\
\text { (5) }\end{array}$ \\
\hline Exercises well-organized & & & $1(7.69 \%)$ & $3(23.08 \%)$ & $9(69.23 \%)$ \\
\hline $\begin{array}{l}\text { Exercises sparked my } \\
\text { interest }\end{array}$ & & & $1(7.69 \%)$ & $4(30.77 \%)$ & $8(61.54 \%)$ \\
\hline Enjoyed participating & & & & $8(61.54 \%)$ & $5(38.46 \%)$ \\
\hline Instructions were clear & & $1(7.69 \%)$ & $1(7.69 \%)$ & $7(53.85 \%)$ & $4(30.77 \%)$ \\
\hline $\begin{array}{l}\text { Can implement } \\
\text { interviewing skills }\end{array}$ & & & $1(7.69 \%)$ & $8(61.54 \%)$ & $4(30.77 \%)$ \\
\hline $\begin{array}{l}\text { Learned a lot from } \\
\text { activities }\end{array}$ & & & & $6(46.15 \%)$ & $7(53.85 \%)$ \\
\hline $\begin{array}{l}\text { Achieved a high level } \\
\text { of confidence with } \\
\text { interviewing skills }\end{array}$ & & & $1(7.69 \%)$ & $11(84.62 \%)$ & $1(7.69 \%)$ \\
\hline
\end{tabular}


the online and classroom group assessed the clarity and effectiveness of the learning exercises that were used. From the data we can conclude that a majority of the students in both groups agreed or strongly agreed with all the characteristics used to assess clarity and effectiveness of the learning exercises.

Table 8 compares the group means and statistical significance of the student responses regarding the clarity and effectiveness of the learning exercises used in each course. On all variables regarding clarity and effectiveness of learning exercises, both groups showed no significant differences in their responses.

\begin{tabular}{|l|c|c|c|c|}
\hline \multicolumn{5}{|l|}{ Table 8: Mean Differences of Clarity and Effectiveness of Learning Exercises } \\
\hline Variables & $\begin{array}{c}\text { Online } \\
\text { Group } \\
\text { (n=16) }\end{array}$ & $\begin{array}{c}\text { Classroom } \\
\text { Group } \\
\text { (n=13) }\end{array}$ & $\mathbf{t}$ & $\mathbf{p}$ \\
\hline $\begin{array}{l}\text { learning exercised } \\
\text { well organized }\end{array}$ & 4.44 & 4.6216 & -.686 & .498 \\
\hline $\begin{array}{l}\text { learning exercised } \\
\text { sparked my interest }\end{array}$ & 4.13 & 4.54 & -1.151 & .260 \\
\hline $\begin{array}{l}\text { I enjoyed } \\
\text { participating in } \\
\text { learning exercises }\end{array}$ & 4.25 & 4.38 & -.499 & .622 \\
\hline $\begin{array}{l}\text { Instructions were } \\
\text { clear }\end{array}$ & 4.44 & 4.08 & 1.302 & .204 \\
\hline $\begin{array}{l}\text { I can implement } \\
\text { beginning skills }\end{array}$ & 3.88 & 4.23 & -1.009 & .322 \\
\hline $\begin{array}{l}\text { My interviewing } \\
\text { confidence is high }\end{array}$ & 3.56 & 4.00 & -1.195 & .242 \\
\hline $\begin{array}{l}\text { Interviewing skills } \\
\text { confidence is high }\end{array}$ & 3.56 & 3.85 & -1.069 & .294 \\
\hline
\end{tabular}

\section{Students' Qualitative Responses}

What follows is a description of the typical responses students provided when asked to add additional comments for each characteristic used to define the clarity and effectiveness of learning exercises.

With respect to organization of the learning exercises, the following is an example of student responses:

"The order of the interview skills was good-beginning with small skills and building upon them."

The following exemplifies how the students felt the learning exercises sparked their interests: 
"I feel that the learning exercises were interesting, because they contained so much information such as: empowering the client to allow him/her to use resources that he/she al ready possess, asking open questions, and not focusing on what's wrong-putting emphasis on what's already working and helping the client to develop skills to strength the resources that al ready exist."

Many students expressed feeling uncomfortable when initially experimenting with practicing interviewing skills. The following is a typical response from students in both groups.

“Doing the taped interviews without previous personal experience was really uncomfortable, I was very unsure of myself."

Students in both groups indicated that the learning exercises used were useful in preparing students for conducting interviews.

"Theselearning exercises werevery helpful in letting meknow which questions to ask and how to ask them."

Table 9 presents combined data from both groups with respect to student perception of the clarity and effectiveness of the learning exercises used for learning interviewing skills. Once again, the majority of all students agreed or strongly agreed with the quality of the learning exercises used.

\begin{tabular}{|l|c|c|c|c|c|}
\hline \multicolumn{7}{|l|}{ Table 9: Clarity and Effectiveness of Learning Exercises } \\
\hline $\begin{array}{l}\text { Online Respondents } \\
\text { Reporting N=13 }\end{array}$ & $\begin{array}{c}\text { Strongly } \\
\text { Disagree } \\
\mathbf{( 1 )}\end{array}$ & $\begin{array}{c}\text { Disagree } \\
\mathbf{( 2 )}\end{array}$ & $\begin{array}{c}\text { Undecided } \\
\mathbf{( 3 )}\end{array}$ & $\begin{array}{c}\text { Agree } \\
\mathbf{( 4 )}\end{array}$ & $\begin{array}{c}\text { Strongly } \\
\text { Agree } \\
\text { (5) }\end{array}$ \\
\hline Exercises well-organized & 0 & 0 & $3(10.34 \%)$ & $8(27.59 \%)$ & $18(62.07 \%)$ \\
\hline $\begin{array}{l}\text { Exercises sparked my } \\
\text { interest }\end{array}$ & 0 & $3(10.34 \%)$ & $1(3.45 \%)$ & $9(31.03 \%)$ & $16(55.17 \%)$ \\
\hline Enjoyed participating & 0 & $1(3.45 \%)$ & $1(3.45 \%)$ & $15(51.72 \%)$ & $12(41.38 \%)$ \\
\hline Instructions were clear & 0 & $1(3.45 \%)$ & $2(6.9 \%)$ & $14(48.28 \%)$ & $12(41.38 \%)$ \\
\hline $\begin{array}{l}\text { Can implement } \\
\text { interviewing skills }\end{array}$ & $1(3.45 \%)$ & $1(3.45 \%)$ & $3(10.34 \%)$ & $15(51.72 \%)$ & $9(31.03 \%)$ \\
\hline $\begin{array}{l}\text { Learned a lot from } \\
\text { activities }\end{array}$ & 0 & $2(6.9 \%)$ & 0 & $16(55.17 \%)$ & $11(37.93 \%)$ \\
\hline $\begin{array}{l}\text { Achieved a high level } \\
\text { of confidence with } \\
\text { interviewing skills }\end{array}$ & $2(6.9 \%)$ & $1(3.45 \%)$ & $3(10.34 \%)$ & $19(65.52 \%)$ & $4(13.79 \%)$ \\
\hline
\end{tabular}

\section{CONCLUDING REMARKS}

Integrating technology into higher education has turned universities' attention to distance education. Although distance education has come a long way in providing quality educational programs to populations that would not otherwise attend universities, some have cautioned years ago that it should not be the driving force behind the development of computer-facilitated instruction (Boot \& Hodgson, 
1987). The main goal for developing technology-supported instructional mediums should not be limited to reaching out to students in isolated areas. Rather, the primary goal for developing technology-supported instructional environments should, first and foremost, be to provide students with a rich, stimulating learning experience. It builds upon the diverse expertise and resources that the medium makes possible and provides students with the opportunity to develop their own individual interests as they discover new meanings and understandings made possible by this unique learning context.

This study addresses the issue of learning efficacy in an online environment, most especially with respect to learning basic interviewing skills considered so essential to the development of effective social work practitioners. Preliminary findings do not indicatemajor differences between student perceptions of thequality of their learning experience and/or their level of confidence, as beginning social work practitioners, irrespective of the learning medium used to learn interview skills.

With further analysis of the data collected for this study, we will be able to determine to what extent learning interviewing skills in the classroom or in a technology-supported learning environment actually transfers to actual practice. As Ehrmann (1995) has suggested, future research and discussion must focus on learning methods specific to the instructional environment and not on the technology itself. The goal of this study is to move our pedagogical discussion towards a greater understanding and appreciation of the conditions that appear to facilitate the creation of a context for good learning, regardless of where or when an educational experience is delivered. By ensuring that we focus on sound principles of good teaching and learning when developing medium-specific learning tasks, our journey in developing quality technology-supported learning systems will greatly be facilitated. I rrespective of the teaching medium we choose, above all else, what remains important is that we continue to strive towards a better understanding of the learning processes that guarantee social work students receive a quality educational experience.

\section{References}

Boot, R.L., \& Hodgson, V.E. (1987). Open Learning: Meaning and Experience. In Hodgson, V.E., \& Mann, S.J., Snell, R. (Eds), Beyond Distance Teaching, Towards Open Learning. Milton Keynes, U.K.: Open University Press.

Brooks, D. (1997). Web-Teaching: A Guideto Designing InteractiveTeaching for theWorld WideWeb. New York: Plenum Press.

Burton D., \& Seabury, B. (1999). The "virtual” social work course; Promises and Pitfall. New Technologyin theHuman Services, 12(3/4), 55-64.

Butterfield, W.H. (1998). Human services and the information economy. Computers in Human Services, 15(2/3), 121-142.

Chang, V.N. \& Scott, S.T. (1999). Basic interviewing skills: A workbook for practitioners. Chicago: NelsonHall.

Clark, F.W., \& Horejsi, C. R. (1979). Mastering specific skills. In F. Clark \& M.L. Arkava (Eds.), The pursuit of competencein social work (pp. 29-46). San Francisco: Jossey-Bass. 
Cook, T.D., Campbell, D.T. (1979). Quasi-Experimentation: Design \& Analysis Issues for Field Settings. Boston: Houghton Mifflin Company.

Doherty, P.B. (1998). Learner Control in Asynchronous Learning Environments. Asynchronous Learning Networks (ALN) Magazine, 2(2).

Ehrmann, S.C. (1995). Asking the Right Questions: What Does Research Tell Us About Technology and Higher Learning? Change, 27(2), 20-27.

Ewell, P., \& Jones, D. (1996). Indicators of "Good Practice" in Undergraduate Education: A Handbook for Development and Implementation: Boulder, Colorado: National Center for Higher Education Management Systems.

Friedman, B. (2002). Using Adult Learning Techniques to Enhance Social Work Education with Technology. Presentation at the Technology Conference for Social Work Education and Practice, Charleston, SC.

Harasim, L. (1999). What areWeLearning about Teaching and Learning Online: An analysis of theVirtualU Field Trials [Online]. Available: http:// www.telearn.ca/g_access/news/vufildtrials.pdf

Harasim, L., Hiltz, S.R., Teles, L., \& Turoff, M. (1995). Learning networks: A field guide to teaching and learning online Cambridge, MA:The MIT Press.

Jaffee, D. (1998). Institutionalized Resistance to Asynchronous Learning Networks. Journal of Asynchronous Learning Networks, 2(2).

Kearsley, G., (1993). Speaking personally with Linda Harasim. The American Journal of Distance Education, 7(3), 70-73.

Kreuger, L. (1997). The end of Social Work. Journal of Social Work Education, 3(1), 19-27.

Macy, J.A., Rooney, R.H., Hollister, C.D., \& Freddolino, P.P. (2001). Evaluation of distance education programs in social work. Journal of Technology in Human Services, 18(3/4), 63-84.

Marson, S.M. (1997). A selective history of Internet technology and social work. Computers in Human Services, 14(2), 35-49.

Ouellette, P, \& Sells, S. (2003). Learning Therapy in a Technology-Supported Instructional Environment. Journal of Systemic Therapies, 22(3), 15-27.

Ouellette, P. (1999). Moving toward technology-supported instruction in human service practice: The "Virtual Classroom." Journal of Technology and Human Services, 16(2/3), 97-111.

Ouellette, P., \& Sells, S. P. (2001). Creating a telelearning community for training social work practitioners working with troubled youth and their families. Journal of Technology and Human Services, 18(1/2),101-116.

TeleLearning Network of Centres of Excellence (TL*NCE) (1995). Research proposal submitted to the NCE Program. Ottawa, Canada: SSHRC.

Trigg, A.M., \& Cordova, F.D. (1987). An integrated model of learning. Radiologic Technology, 58, $431-436$

\section{Author's Note:}

Address correspondence to: Philip Ouellette, Ph.D., School of Social Work, Indiana University, 902 West New York Street, ES 4153, Indianapolis, IN 46202, USA. E-mail: pouellet@iupui.edu 